Campos Neutrais - Revista Latino-Americana de Relações Internacionais Vol. 2, $\mathrm{N}^{\circ}$ 3, Setembro-Dezembro de 2020. Santa Vitória do Palmar - RS.

\title{
Crise iemenita: da atuação de mercenários contratados à jurisdição do tribunal penal internacional frente às violações de direito humanitário
}

\author{
Tatiana de A. F. R. Cardoso Squeff \\ Beatriz Patriota** $^{* *}$
}

Resumo: A Guerra no Iêmen completa, em 2020, seis anos de duração, sendo, rotineiramente, taxada como a pior crise humanitária da atualidade, haja vista o número de fatalidades já ter ultrapassado os 100.000 mortos. Apesar de se tratar de um conflito interno, as hostilidades envolvem inúmeras frentes, tanto estatais como não estatais, sendo, por isso, de difícil resolução. Um aspecto, porém, que torna o conflito ainda mais peculiar é o uso elevado de mercenários, isto é, combatentes privados que são apontados como causadores de diversas atrocidades classificadas como crimes de guerra e crimes contra a humanidade pela sociedade internacional. Nesse cenário, um questionamento recorrente tem sido a possibilidade de levar essas situações a conhecimento do Tribunal Penal Internacional (TPI), para que o mesmo possa julgar tais atores por suas condutas, sendo este o objeto central de análise do presente artigo, o qual se realiza através do método hipotético-dedutivo e desde um recorte descritivo-explicativo. Assim sendo, partindo da análise bibliográfica e documental, após verificadas as pormenoridades do conflito iemenita e estudada a atuação das partes envolvidas, segue-se para o exame do uso do TPI, concluindo-se que, apenas, os mercenários oriundos de Estados-partes do Estatuto de Roma é que poderiam ser julgados, em que pese a promotoria da Corte ter rechaçado, em 2019, a sua atuação para julgar quaisquer envolvidos no conflito.

Palavras-chave: Iêmen. Direito Humanitário. Mercenários. Empresas Militares Privadas. Tribunal Penal Internacional.

\section{Yemen crisis: from the use of contracted mercenaries to the jurisdiction of the international criminal court due to humanitarian law violations}

\begin{abstract}
The War in Yemen completes, in 2020, six years of duration, being routinely rated as the worst existing humanitarian crisis, given that the number of fatalities has already exceeded 100,000 dead. Despite being an internal conflict, hostilities involve numerous fronts, both state and nonstate, what makes it difficult to resolve. One aspect, however, that makes the conflict even more peculiar is the use of mercenaries, that is, private combatants who are identified as the cause of several atrocities classified as war crimes and crimes against humanity by the international society. In light of this scenario, a recurring question has been the possibility of bringing these situations to the attention of the International Criminal Court (ICC), so that it can judge these actors by their conduct, being this the central object of analysis of the article, which is carried out through the hypothetical-deductive method and from a descriptive-explanatory view. Therefore, parting from a bibliographic and documentary analysis, after verifying the details of the Yemeni conflict and studying the performance of the parties involved, we examine the performance of the ICC, concluding that only mercenaries from State-parties to the Rome Statute could be tried by it, despite the prosecution of the Court having rejected, in 2019, the complaints intended to try those involved in the conflict.
\end{abstract}

Keywords: Yemen. Humanitarian Law. Mercenaries. Private Military Companies. International Criminal Court.

\section{Introdução}

Atualmente, o conflito no Iêmen é considerado pelas Nações Unidas (ONU) como a pior crise humanitária do mundo. As causas da classificação são diversas, assim como seus

\footnotetext{
* Professora permanente do Programa de Pós-Graduação em Direito da Universidade Federal de Uberlândia.

** Graduanda do $4^{\circ}$ período de Relações Internacionais na Universidade Federal de Uberlândia (UFU). Membro do Grupo de Estudos e Pesquisa em Direito Internacional (GEPDI/CNPq) na citada Universidade.
} 
fatores. Estima-se que $80 \%$ da população necessita de ajuda humanitária, uma vez que os efeitos da crise afetam, diretamente, as condições básicas de sobrevivência da pessoa humana: apenas $51 \%$ do sistema de saúde ainda funciona; 20 milhões de iemenitas sofrem de insegurança alimentar; o acesso ao saneamento é dificultado, o que contribui, também, para um dos maiores surtos de cólera do mundo (UNRIC, 2020).

As origens do conflito se remetem a 2011, sob o contexto da Primavera Árabe, movimento que pretendia a instituição de regimes democráticos no mundo árabe, a partir da destituição de regimes autocráticos, que se perpetuaram por anos. A partir disso, o Iêmen, considerado, atualmente, como um dos países árabes mais pobres do mundo enfrenta consequências irreparáveis, fruto de uma transição política falha, a partir da queda do então presidente Ali Abdullah Saleh frente ao vice, Abdrabbuh Mansour Hadi.

A questão iemenita torna-se ainda mais complexa pela quantidade de diferentes atores envolvidos, dentre eles: grupos internos, Estados da região (como os Emirados Árabes Unidos, Arábia Saudita e Irã) e, até mesmo, grandes potências ocidentais (como Estados Unidos, França e Reino Unido) que atuam no território em prol de seus interesses, principalmente, geopolíticos; afinal, o país é localizado no estreito de Bab Al-Mandab, que liga o Mar Vermelho ao Golfo de Áden, sendo uma importante passagem de navios petroleiros (BBC, 2018).

Por sua vez, os citados Estados, frequentemente, promovem investidas armadas na região, mesmo que de maneira indireta, afetando, principalmente, a população civil, configurando em violações gravíssimas aos direitos humanos, uma vez que ferem, diretamente, os princípios que regem a sociedade internacional e são estabelecidos pelo Direito Internacional Humanitário e pelo Direito Internacional dos Direitos Humanos ${ }^{1}$, logo comum a todos os Estados, notadamente pelo caráter jus cogens de grande parte dessas regras. Estima-se que, desde 2015, mais de 100.000 pessoas já morreram no conflito e cerca de 3,65 milhões de pessoas já foram deslocadas de suas casas (BBC, 2020)2.

Apesar da tentativa de cessar-fogo, através do Acordo de Estocolmo, de 2018, e do Acordo de Riade, de 2019, a crise política continua a se intensificar, assim como os problemas humanitários (ONU, 2019). Novos atores internacionais surgem para fomentar a

\footnotetext{
${ }^{1}$ Ambas os ramos jurídicos possuem como finalidade a estipulação de normas que garantam proteção à vida, à saúde e à dignidade humana, ou seja, os direitos fundamentais. Além disso, enfatizam a proibição da tortura, de atos cruéis e de discriminação (ICRC, 2002).

2 Em outubro de 2019, o Projeto de Localização de Conflitos Armados e Dados de Eventos (ACLED) registrou o número de mortes e incluiu que destes, 12.000 foram resultados de ataques diretos a civis. Em 2020, a ONU enfatizou que 7.700 civis teriam sido mortos apenas no mês de março, vítimas de ataques aéreos promovidos pela coalizão da Arábia Saudita. (BBC, 2020).
} 
ocorrência de crimes de guerras, decorrentes de ataques aéreos, de movimentos de artilharia e de tortura contra as partes envolvidas, como é o caso de mercenários vinculados a Empresas Militares de Segurança Privada, de diferentes nacionalidades, contratados, principalmente, pelos Emirados Árabes Unidos (EAU).

Nesse cenário, o Tribunal Penal Internacional (TPI) torna-se um objeto importante de reflexão nos debates sobre a crise: teria este órgão jurisdição para atuar nessa situação em prol da responsabilização desses novos atores, almejando a assecuração dos direitos humanos da população iemenita e, por fim, amenizando os efeitos da crise? Isso porque esta Corte é responsável pela investigação e pelo julgamento de crimes internacionais promovidos por indivíduos provenientes de Estados-partes do Estatuto de Roma ou cometidos nos territórios de seus membros, assegurando que os perpetradores de tais violações não restem impunes, por conseguinte, coibindo a prática de atos tão lesivos à humanidade.

Para tanto, a presente pesquisa utiliza-se do método hipotético-dedutivo para que, uma vez conhecendo as pormenoridades do conflito e das condutas dos atores e sujeitos envolvidos, se possa verificar o uso da jurisdição do TPI. No que concerne aos objetivos, estes serão analisados de duas maneiras: descritiva, com a exposição de fatos, caracterizações e regras envolvidas; e explicativa, buscando analisar e compreender a importante influência dos mercenários neste conflito, bem como sua relação com os Estados frente ao conflito iemenita e com a jurisdição do Tribunal Penal Internacional frente às violações de direito internacional cometidas por eles. Quanto ao procedimento, adota-se a técnica bibliográfica e documental, ambos selecionados qualitativamente, em que pese não se tenha o condão de exaurir as fontes sobre o tema.

\section{Panorama geral do conflito: uma apresentação dos fatores e atores}

Apesar de uma fracassada tentativa de implementação de um regime democrático com a ascensão de Hadi ao poder, o Iêmen, na realidade, passou a enfrentar uma intensa instabilidade política, que resultou numa fragmentação do território em vários locais de poder, controlados por diferentes grupos, dentre os quais, destacam-se: as forças do atual governo $(\mathrm{ROYG})^{3}$, o grupo dos Houthis ${ }^{4}$, o grupo Al Qaeda da Península Arábica

\footnotetext{
${ }^{3}$ Refere-se ao atual governo reconhecido internacionalmente e é liderado pelo Hadi desde 2012. Organismo apoiado pela coalizão liderada pela Arábia Saudita, desde 2015 (SHARP, 2019).

${ }^{4}$ Movimento insurgente, predominantemente vinculado à vertente xiita Zaid, formado no Norte do país, mais especificamente, na província de Sa'dah. Aliado do presidente Saleh até 2017 (SHARP, 2019).
} 
Campos Neutrais - Revista Latino-Americana de Relações Internacionais Vol. 2, $\mathrm{N}^{\mathrm{O}}$ 3, Setembro-Dezembro de 2020. Santa Vitória do Palmar - RS.

(AQAP) $^{5}$ e o Conselho de Transição do Sul (STC, na sigla em inglês) ${ }^{6}$. Além disso, a transição política desastrosa impulsionou uma grave crise econômica, gerando desemprego, escassez de serviços de saneamento básico e precária infraestrutura, o que possibilitou uma maior adesão ao movimento dos Houthis, portanto, uma força maior para esses expandirem seus controles territoriais.

Em 2014, após tomar a capital Sanaa, os Houthis passaram a controlar, também, o Porto de Hodeidah ${ }^{7}$, o segundo maior porto do Iêmen, que garante acesso direto ao Mar Vermelho - um ponto geopolítico estratégico, principalmente, no que concerne à passagem de navios petroleiros e à chegada de alimentos e de medicamentos. Tal fato permite compreender um dos grandes fatores que causam a crise humanitária iemenita: o país já era extremamente dependente de importações, registrando cerca de $90 \%$ de seus alimentos, combustível e medicamentos provenientes do exterior, ao passo que $70 \%$ dessas importações chegavam através do referido Porto (APH, 2019).

Ato contínuo, os insurgentes se aliaram às forças leais do ex-Presidente Saleh, na tentativa de expandir sua influência e controle por todo o território nacional. Essa ação acarretou na fuga, em 2015, do então presidente Hadi para o país vizinho, Arábia Saudita. Sob esse cenário, além dos grupos já citados, os Estados passaram a se destacar no conflito e tornaram-se atores internacionais fundamentais no seu decorrer, intensificando a fragmentação do poder observada no território e iniciando o que se conhece por 'Guerra de Procuração'.

Com a fuga de Hadi, a Arábia Saudita forma, então, uma coalizão com outros sete Estados árabes ${ }^{8}$, sob o pressuposto de uma potencial expansão da influência iraniana na região - a partir de um hipotético apoio desta República Islâmica, de maioria xiita, ao grupo Houthis, também de maioria xiita. Frisa-se que a coalizão recebeu apoio estratégico de países ocidentais, como Estados Unidos, Reino Unido e França (BBC, 2020). Desde a sua formação, estima-se que esta já conduziu 18.000 ataques aéreos, dos quais um terço atingiu alvos não militares (APH, 2019). No mesmo ano, a coalizão se estabeleceu na

\footnotetext{
${ }^{5}$ Opera, no Iêmen, desde 2009, atuando em províncias no Sul do país (SHARP, 2019). É considerada por muitas agências de inteligência como o braço mais perigoso do grupo Al Qaeda por seu conhecimento técnico e alcance mundial (BBC, 2018).

${ }^{6}$ É um grupo separatista do Sul, apoiado pelos Emirados Árabes Unidos desde 2017. É comandado pelo general Aidarous Al Zubaidi, governador de Áden (SHARP, 2019).

${ }^{7}$ Os insurgentes bloquearam e detiveram os alimentos e os medicamentos que chegavam pelo Porto, assim como negaram o acesso a esses recursos pela população. Estima-se que, em decorrência desse ato, que fomentou a crise humanitária no país, 14 milhões de pessoas se encontram em situação de fome extrema ou em meio a doenças (HRW, 2019).

${ }^{8}$ Emirados Árabes Unidos, Qatar, Kuwait, Bahrein, Egito, Jordânia, Marrocos e Turquia (ARWA, s/d).
} 
cidade de Áden, resultando na expulsão dos Houthis e de seus aliados, em que pese Hadi continuasse exilado e os insurgentes, ainda, controlassem a capital Sanaa e o porto de Hodeidah.

Apesar de oito países formadores da coalizão, os mais influentes, certamente, são a Arábia Saudita e os Emirados Árabes Unidos (EAU), isso porque adentrar nessa aliança possibilitou para este último uma maior aproximação com os Estados Unidos, que concede apoio de inteligência e estratégico, principalmente a partir do fornecimento de armamentos, garantindo-lhes maior força para conter grupos terroristas, como no caso do Iêmen, a AQAP, que atua no sul do país (SHARP, 2019). Nesse sentido, a aliança permite aos EAU, acima de tudo, uma maior influência em sua área de interesse econômico, principalmente, no âmbito comercial e energético. Destaca-se, aqui, o caráter não internacional do conflito ${ }^{9}$, já que, apesar de contar com o apoio direto de Estados árabes e indiretos de grandes potências, as hostilidades têm por atores principais o governo central (na figura de Hadi) e as forças Houthi.

Em 2017, o conflito voltou a se intensificar, com uma maior fragmentação entre as partes envolvidas. Saleh, que desde 2015 era aliado dos Houthis, acusou-os de aliança com o Irã, como forma de atrair apoio da Arábia Saudita e dos Estados Unidos. A ação resultou no assassinato do ex-Presidente e na retomada de Sanaa pelos insurgentes. De outro lado, após uma acusação de que os EAU estariam atuando em divergência aos interesses do governo central iemenita e, consequentemente, prejudicando a integridade territorial e a sua soberania, o referido Estado passou a apoiar o STC), que assim, conseguiu conquistar a cidade de Áden (BBC, 2018). Ademais, o lançamento de um míssil em Riade (Arábia Saudita) provocou uma maior reação da coalizão, que fortaleceu seu bloqueio ao Iêmen fato este que foi condenado pela ONU, através do Subsecretário-Geral Adjunto para os Assuntos Humanitários, Mark Lowcock, pois poderia resultar em uma das piores crises de fome em décadas ${ }^{10}$ (YEMEN..., 2017).

Uma nova ofensiva é promovida pela coalizão no ano seguinte, na tentativa de tomar o controle da cidade de Hodeidah, o que foi, novamente, condenado pela ONU, uma vez que o porto é uma importante entrada de recursos e de matéria-prima. Para tanto, a Organização iniciou tentativas de negociação para promover um cessar-fogo entre as

\footnotetext{
9 "Um conflito armado não internacional (ou interno) refere-se a uma situação de violência que envolve confrontos prolongados entre forças governamentais e um ou mais grupos armados organizados, ou esses grupos entre si, surgidos no território de um Estado" (LAWAND, 2012)

${ }^{10}$ Em 2018, a ONG Save de Children, baseando-se em dados provenientes de relatórios formulados pela ONU, estimou que uma média de 100 crianças morriam por dia, decorrente de doenças ou de fome extrema. Entre 2015 e 2018, foi contabilizada a morte de 85.000 crianças por má nutrição (SHARP, 2019).
} 
partes, que só ocorreria seis meses depois, a partir do chamado 'Acordo de Estocolmo', relatado pelo Enviado Especial das Nações Unidas para o Iêmen, Martin Griffiths (UN, 2018). O Acordo consiste em três pontos principais: (a) o cessar-fogo por volta da cidade de Hodeidah; (b) a troca de prisioneiros entre as partes envolvidas; (c) uma declaração de entendimento proveniente de todas as partes, garantindo a formação de um Comitê para a discussão sobre a cidade de Taiz, que foi, completamente, destruída devido ao conflito (SHARP, 2019).

Muito embora tenha o acordo sido firmado e, certamente, asseguradas melhorias em questões de segurança e de redução da violência, relatórios formulados, em 2019, por Griffiths, atentam para o fracasso na desmilitarização na região, visto que os Houthis continuavam a atuar, mesmo que esporadicamente, o que denota uma possível ameaça de violação do cessar-fogo (SHARP, 2019). Apesar do acordo, ao final de 2018, estipulou-se que, desde 2016, cerca de 56.000 pessoas haviam sido mortas em decorrência do conflito, entre elas, civis e combatentes, o que remete a uma média de 1.500 mortes por mês (AHP, 2019).

Ao final de 2019, o número já havia ultrapassado os 100.000 mortos (BEAUMONT, 2019). Isso decorre do fato de, neste ano, terem sido observadas eclosões de uma série de novos conflitos em áreas que costumavam ser ofuscadas pela questão em torno do porto de Hodeidah. Já citada no 'Acordo de Estocolmo', a cidade de Taiz foi controlada pelos Houthis, de 2015 a 2017 e recuperada pelo governo central apoiado pela coalizão, o qual controla a região até hoje (INTERNATIONAL CRISIS GROUP, 2019). Contudo, a cidade comportou grandes desastres humanitários; estima-se que houve uma perda de um terço de sua população anterior e voltou a ganhar destaque a partir de uma intensificação de divergências internas, entre o governo central - na figura do governador de Taiz, Nabeel Shamsan - e uma coalizão de forças anti-Houthis, que se encontra, constantemente, fragmentada por uma série de embates ocorridos entre o grupo de combatentes fiéis ao líder salafista Abu Al-Abbas e a combatentes filiados ao Islah, líder sunita do Iêmen partido político ${ }^{11}$ (INTERNATIONAL CRISIS GROUP, 2019).

Além desta, intensificou-se, também, o embate entre as forças governamentais e as

\footnotetext{
${ }^{11}$ Especificamente, muitos observadores iemenitas apontam os Emirados Árabes Unidos como um dos os principais apoiadores do grupo fiel a Al-Abbas, uma vez que a presença deste, na cidade de Taiz, contribuiria para frear a presença de Islah na cidade, bem como aumentar a instabilidade na região controlada pelo governo central, o que provocou um questionamento desses dois grupos de oposição quanto aos interesses dos Emirados Árabes em apoiar os grupo de Al-Abbas, temerosos de que o controle da cidade de Taiz possibilitasse uma ligação direta à cidade de Áden - controlada pelo STC e influenciado, também, pelo país árabe, o que acarretaria num aprofundamento ainda maior das hostilidades entre os grupos da região (INTERNATIONAL CRISIS GROUP, 2019).
} 
Campos Neutrais - Revista Latino-Americana de Relações Internacionais Vol. 2, $\mathrm{N}^{\mathrm{O}}$ 3, Setembro-Dezembro de 2020. Santa Vitória do Palmar - RS.

forças do STC, motivado pela acusação destes últimos a uma má administração de Hadi, clamando por uma nova negociação de divisão do poder, em que pese as forças do Sul serem apoiadas pelos EAU e declararem a sua retirada do conflito em julho de 2019, após uma série de acusações internacionais que remetem ao cometimento de atos configurados como crime de guerra (REUTERS, 2019). Em agosto do mesmo ano, foram relatados novos ataques a Áden, de autoria do STC, que passou a controlar acampamentos militares e promoveu ataques às instituições do Estado, tentando dominá-las, também, a partir do uso da força, o que acarretou em mais um violento episódio do conflito com centenas de feridos (REUTERS, 2019).

Nesse momento, cabe ressaltar a estratégia adotada pelos EAU para manter o controle da sua região foco - o Sul -, que consiste em uma integração dessas milícias já citadas e de outras mais, denominada 'Cinturão de Segurança', o qual, apesar de líderes e crenças diferentes entre os grupos formadores, possui como objetivo central a repressão da Al-Qaeda, dos Houthis e, até mesmo, do Estado Islâmico, em que o apoio do país árabe ocorre a partir da concessão de armamentos e treinamento militar, terminando por contribuir para a manutenção do seu poder nas províncias sulistas (HERAS, 2018).

Ato contínuo, durante uma sessão do Conselho de Segurança da ONU, em 20 de agosto de 2019, Griffiths apresentou um novo relatório sobre a situação na região:

I hope that all Yemeni stakeholders from all parts of the country take the events in Aden as a clear sign that the current conflict must be brought to an end swiftly and peacefully and in a manner that addresses the needs of Yemenis across the country. The implementation of the Stockholm Agreement is politically significant and has had tangible benefit on the ground, but surely that cannot be a precondition for achieving peace in all of Yemen. Every additional day of this conflict adds to the tragedy and the misery; no country can tolerate these stresses and the stresses of internal conflict indefinitely. (UN, 2019, p. 4; OSESGY, 2019) ${ }^{12}$

No mesmo relatório, atentou, também, para uma nova ascensão do Al Qaeda que se utilizaria da fragmentação das diversas frentes para expandir seu poderio na região:

In this context, and with these events in mind, we must also be alive to the danger of the resurgence of the activities of violent extremist groups. The

\footnotetext{
12 Tradução livre: Agora, espero que todas as partes interessadas do Iêmen, de todas as partes do país, considerem os eventos em Aden como um sinal evidente de que o conflito atual deve ser encerrado - de forma rápida e pacífica e de uma maneira que atenda às necessidades dos iemenitas em todo o país. A implementação do Acordo de Estocolmo é politicamente significativa e teve benefícios tangíveis no terreno. Mas, certamente, essa não pode ser uma precondição para alcançar a paz em todo o Iêmen. Cada dia a mais deste conflito aumenta o total da tragédia e da miséria, e nenhum país pode tolerar essas tensões do conflito interno indefinidamente.
} 
Council will recall that Al-Qaida in the Arabian Peninsula has taken control of the capitals of Abyan and Hadramaut for significant periods of time in recent years. During the past month alone, we have seen attacks by Al-Qaida and by the so-called Islamic State in Aden, Abyan and AlBaydah governorates. The further fragmentation of the security situation in Aden and other areas almost certainly will allow those activities to expand and gather momentum once again, as we have seen before, with a terrible impact on the civilian population and on prospects for future stability in this key strategic location. (UN, 2019, p. 4; OSESGY, 2019). ${ }^{13}$

Após meses de instabilidade, a fim de garantir uma resolução ao conflito ocorrido no sul do país, o governo central e o STC firmaram o 'Acordo de Riade', em novembro de 2019, que objetiva um compartilhamento de poder entre as duas instâncias ${ }^{14}$, assim como a retomada de poder da cidade de Áden ao governo reconhecido internacionalmente, ou seja, às forças de Hadi $(\mathrm{G} 1,2019)$. Apesar de firmado com consentimento de ambos os lados, as forças do STC voltaram a apontar a má administração do governo central, inclusive, para prover serviços básicos à população, e, em abril de 2020, se autoproclamou como instância governamental de Áden, retomando o controle da cidade e rompendo com o ora firmado com o governo central, orquestrado pelo Estado saudita (AFP, 2020). Em julho deste mesmo ano, os separatistas renunciaram à declaração de autonomia a partir de uma nova proposta formulada pela Arábia Saudita, nos moldes do Acordo de Riade e como forma de aplicar suas diretrizes de maneira mais célere, que ainda está em andamento (FRANCE PRESSE, 2020).

Assim, ressalta-se a natureza multifacetada do conflito, com diversos atores nacionais e internacionais envolvidos que, motivados por seus interesses, em particular, os geopolíticos, atuam, no país, de modo a intensificar, cada vez mais, a crise humanitária a partir da continuação das hostilidades, as quais, porém, não têm respeitado os limites legais impostos pelo Direito Internacional Humanitário, gerando um questionamento sobre a possibilidade de responsabilização dos envolvidos.

\footnotetext{
13 Tradução livre: Neste contexto e com estes eventos em mente, devemos, também, estar atentos ao perigo de um ressurgimento das atividades de grupos extremistas de violência. Este Conselho recordará que a AlQaeda, na Península Arábica, AQAP, assumiu o controle das capitais de Abyan e Hadramout por períodos significativos nos últimos anos (OSESGY, 2019). Só durante o mês passado, vimos ataques da Al-Qaeda e do chamado Estado Islâmico nas províncias de Aden, Abyan e Al-Bayda. E uma maior fragmentação da segurança em Aden e em outras áreas, certamente, permitirá que essas atividades se expandam e ganhem impulso mais uma vez, como vimos antes, com um terrível impacto sobre a população civil e com perspectivas de estabilidade futura nesta estratégia chave localização

${ }^{14} \mathrm{O}$ documento, também, prevê a formação de um governo de 24 ministérios distribuídos entre as províncias do norte e do sul $(\mathrm{G} 1,2019)$.
} 


\section{A atuação das partes envolvidas e o surgimento de um novo ator internacional, o mercenário}

A partir dos anos 1960, com o surgimento de inúmeros conflitos atrelados à descolonização e à consequente multiplicação de novos militares estrangeiros para atuarem em tais conflitos, observou-se a necessidade de promover uma definição legal para o conceito de 'mercenários'. Sendo assim, durante uma Conferência Diplomática sobre a Reafirmação e o Desenvolvimento do Direito Internacional Humanitário aplicável aos conflitos armados, em 1977, adotou-se o Protocolo Adicional I às Convenções de Genebra (ICRC, 1977, art. 47), definindo mercenário como todo aquele que seja recrutado para combater, num conflito armado, sob o pressuposto de obter uma vantagem pessoal no que concerne, principalmente, a uma remuneração material superior à que era prometida a este em funções análogas nas Forças Armadas, não sendo um nacional de alguma face envolvida. Além disso, em 1989, foi criada a 'Convenção Internacional contra o Recrutamento, Uso, Financiamento e Treinamento de Mercenários', com o intuito de enfatizar a ilicitude de tal ação (ONU, 1989).

Em complemento, McFate (2019) destaca o caráter de globalização da utilização de uma força privada a partir do contrato de mercenários e se utiliza de cinco características para distingui-los de soldados ou de agentes não estatais, como os terroristas: (a) são “entidades" que buscam maximizar seus lucros; (b) são estruturados como negócio; (c) não são seguranças domésticos, sendo estimados/utilizados por outros Estados; (d) se utilizam de força à maneira militar, desrespeitando normas jurídicas; (e) representam a mercantilização de conflitos armados, uma vez que são mais baratos em países de desenvolvimento (MCFATE, 2019).

Nesse sentido, em que pese haja regras que excluam os mercenários de uma proteção específica no âmbito dos conflitos armados (enquanto combatente) e advoguem contra o seu uso, nota-se a íntima relação entre o emprego de mercenários e a privatização dos conflitos armados, fazendo com que cresça o questionamento, na atualidade, em torno da necessidade de restringir o uso do segundo ${ }^{15}$, na medida em que a expansão da contratação de serviços militares por Estados, por grupos paramilitares, por grandes corporações, etc. (GUEDES, 2017, p. 24-25) termina por fazer com que, ao fim e ao cabo, mercenários atuem nos conflitos.

$\mathrm{Na}$ virada deste século, a partir das empreendidas dos Estados Unidos em países

\footnotetext{
${ }^{15}$ Existe, inclusive, um Grupo de Trabalho da ONU sobre a Utilização de Mercenários, criado em 2005, que advoga para o citado fim (UNICRIO, 2010).
} 
como Afeganistão e Iraque, a empresa de segurança privada Blackwater ganhou destaque no cenário de conflitos no Oriente Médio por fornecer combatentes que recebiam altas remunerações a Estados envolvidos nos conflitos para atuarem na região e para defenderem os interesses destes, ou seja, remetendo à definição que caracteriza um mercenário (GUEDES, 2017, p. 26). Apesar disso, nenhum dos Estados, citados acima, é parte da Convenção de 1989, em vigor desde 2001; no que tange ao conflito do Iêmen, apenas, Arábia Saudita a compõe desde 1997 (UN, 2020), não sendo, assim, suficiente o regramento contido no Protocolo I, de 1977, para evitar que tais indivíduos sejam empregados nas hostilidades.

Nesse sentido, em 2008, a partir de uma iniciativa conjunta entre o Departamento Federal Suíço de Relações Exteriores e o Comitê Internacional da Cruz Vermelha, formulou-se o 'Documento de Montreux', que em princípio concebeu a adesão de 17 Estados para regulamentar as obrigações jurídicas internacionais dos Estados no que compete às Empresas Militares de Segurança Privada (EMSPs) e suas atividades em conflitos armados. Assim, no que se refere aos Estados Contratantes, estabelece que "estes têm a obrigação, dentro de seus poderes, de garantir que as EMSPs contratadas respeitem o Direito Internacional Humanitário, em particular" (ICRC, 2008, item 1[A]- tradução nossa):

(a) garantir que as EMSPs contratadas e seus funcionários estejam cientes de suas obrigações e se preparem em conformidade à estas;

(b) não incentivar ou auxiliar, assim como tomar medidas apropriadas para prevenir quaisquer violações de Direito Internacional Humanitário por funcionários das EMSPs;

(c) tomar medidas para reprimir violações de Direito Internacional Humanitário cometidas por funcionários das EMSPs através de meios apropriados, como regulações militares, ordenamento administrativo e outras medidas regulatórias, bem como, sanções administrativas, disciplinares e jurídicas (ICRC, 2008, item 1[A]- tradução nossa).

Além disso, o documento estipula que estes Estados são responsáveis por adotar leis ${ }^{16}$ e outras medidas internas para implementar suas obrigações em relação ao Direito Internacional, e, também, por prevenir e investigar ações das EMSPs que possam ensejar a sua violação, ao passo que os indivíduos que cometerem violações devem ser punidos por estes Estados, incluindo-se a possibilidade de extradição ou de entrega ao Tribunal Penal

16 A Suíça, em 2015, sancionou uma lei voltada a regular o mercado de serviços militares privados, "proibi[ndo] a participação de firmas suíças em hostilidades e submete[ndo] as empresas de segurança a estrito controle governamental. [...] [A] legislação exclui de seu escopo as empresas envolvidas na proteção de pessoas, na vigilância de bens e propriedades e na segurança de eventos" (GUEDES, 2017, p. 46). 
Campos Neutrais - Revista Latino-Americana de Relações Internacionais Vol. 2, $\mathrm{N}^{\mathrm{O}}$ 3, Setembro-Dezembro de 2020. Santa Vitória do Palmar - RS.

Internacional, a depender da situação (ICRC, 2008).

De mesma forma, o documento determina que os Estados onde atuam essas EMSPs têm obrigações idênticas aos tópicos (b) e (c) citados anteriormente, alterando o tópico (a), no qual frisa que "estes devem disseminar, mais abrangentemente possível, o texto das Convenções de Genebra e outras normas relevantes de Direito Internacional Humanitário entre as empresas e seus funcionários" (ICRC, 2008 - tradução nossa). Dessa maneira, o documento fornece bases para uma regulamentação não só da ação dos Estados, mas também, de modo indireto, da conduta das EMSPs, muito embora, por se tratar de uma soft law, ela não tenha força de lei, funcionando, apenas, enquanto uma recomendação, portanto não sendo comumente implementada pelas partes.

Sob esse cenário de investidas militares, em 2015, o jornal The New York Times publicou, pioneiramente, uma matéria relatando que os EAU enviaram, secretamente, cerca de 450 mercenários latino-americanos - em sua maioria, colombianos, salvadorenhos, chilenos e panamenhos - para lutar no conflito no Iêmen, utilizando-os como estratégia militar para controle e para a invasão de territórios de interesse (HAGER; MAZZETTI, 2015). Imperioso acrescentar que o envio foi relacionado a uma empresa ligada à Blackwater, Reflex Responses, que, de acordo com fontes, era administrada por militares dos EAU ${ }^{17}$ (HAGER; MAZZETTI, 2015). No mesmo ano, seis mercenários colombianos e um australiano foram mortos durante um confronto no país e estavam diretamente associados à Blackwater (SAFI; ROBERTSON, 2015; GUEDES, 2017, p. 26), enfatizando o caráter de mercantilização dessa contratação, evidenciando, ainda, mais um Estado envolvido indiretamente no conflito - a Austrália (HAGER; MAZZETTI, 2015).

Continuamente, além de uma ligação desses mercenários com empresas privadas, também, se observa uma relação direta com grandes potências ocidentais, como Reino Unido, Alemanha, França e, principalmente, Estados Unidos, sendo importante salientar a importância deste último, visto que, entre 2000 e 2015, dentro das ações promovidas pelo Plano Colômbia ${ }^{18}$, o país investiu cerca de 7 bilhões de dólares para treinar, orientar e

\footnotetext{
${ }^{17}$ Operações promovidas por colombianos, no território iemenita, eram efetuadas sob o comando de militares emirates, com co-cordenação de comandantes colombianos. As ações se resumiam ao combate urbano, e, no deserto, ao controle de territórios e da segurança de bases e caravanas (EL TIEMPO, 2015). Além dessas empresas, a Global Enterprises, comandada por Oscar Garcia Batte, co-comandante da brigada de tropas colombianas relacionadas aos EAU, também, se destaca nas operações de recrutamento de mercenários colombianos (HAGER; MAZZETTI, 2015).

${ }^{18}$ Consiste em um plano diplomático bilateral entre os Estados Unidos e a Colômbia, com o objetivo estadunidense de solucionar as questões de narcotráfico e os conflitos internos no país latino-americano. Estima-se que $71 \%$ do investimento dos EUA reverteu-se para mobilidade aérea, erradicação de plantações ilícitas, interdições de drogas, treinamento e desenvolvimento militar, inteligência e centros de treinamento e manutenção (BBC, 2016).
} 
Campos Neutrais - Revista Latino-Americana de Relações Internacionais Vol. 2, $\mathrm{N}^{\mathrm{O}}$ 3, Setembro-Dezembro de 2020. Santa Vitória do Palmar - RS.

equipar forças de segurança da Colômbia (BBC, 2016). O referido ato acarretou na possibilidade de uma 'exportação de segurança' relacionada ao país latino-americano, visto que as forças eram, extremamente, bem treinadas e, na efervescência da ambição desses militares, prometidos de remuneração melhor do que em órgãos nacionais, rumaram para o conflito no Iêmen através das EMSPs (BBC, 2016).

Além disso, estima-se que cerca de 30.000 soldados vinculados a países latinoamericanos que "exportam" mercenários estavam sendo treinados pelo governo estadunidense, ao passo que, em 2015, já haviam 100 salvadorenhos em operação no Iêmen, que diferentemente dos colombianos, eram contratados por uma empresa nacional ligada à Northrup Grumman (CARLSEN, 2015). Há relatos, ainda, de ex-soldados americanos atuando no conflito por meio da operação mercenária promovida pela empresa Spear Operations Group ${ }^{19}$ (CARLSEN, 2015).

Intrínseco às operações de recrutamento se encontra, também, um intenso fluxo na indústria bélica principalmente no que concerne ao abastecimento de armas e de componentes para a produção de equipamentos militares, como aviões; no conflito, observa-se o fornecimento desses instrumentos pelas grandes potências ocidentais às forças da coalizão e, de outro lado, pelo Irã às forças do movimento Houthi (TODD, 2019; EMMONS, 2019). Esse grande contingente de armamentos fornecidos alimentam o caráter sangrento e de crise humanitária pela qual o Iêmen ${ }^{20}$ sobrepassa, assim como incentiva a continuação de investidas militares promovidas pelas partes envolvidas, diretamente, no conflito, o que justifica as acusações frente ao Tribunal Penal Internacional, direcionadas, em particular, aos EAU, uma vez que este contribui, diretamente, para os ataques ocorridos contra civis, para as mortes destes, para os desaparecimentos forçados, para os abusos sexuais e para a utilização de crianças no conflito - ações abertamente contrárias ao direito internacional humanitário (RYAN, 2020).

\footnotetext{
${ }^{19}$ Os mercenários contratados atuam para o contraterrorismo e assassinatos em série. Atenta-se aqui para o fato de que os Estados Unidos, por meio de seu Departamento de Estado, é responsável pela regulamentação das atividades dessas empresas privadas que fornecem serviços militares a estrangeiros e afirma nunca ter concedido autonomia para operações como essas. O mesmo é válido para outras empresas estadunidenses que protagonizam essas contratações mercenárias, como a Blackwater, o que não é observado (ROSTON, 2018).

20 “Apesar das graves violações atribuídas aos EAU e às milícias que apoiou, os seguintes estados forneceram recentemente armas aos Emirados Árabes: Austrália, Bélgica, Brasil, Bulgária, República Tcheca, França, Alemanha, África do Sul, Coréia do Sul, Turquia, Reino Unido e EUA, entre outros. Muitos dos Estados que continuam a fornecer armas para os Emirados Árabes Unidos são parte do Tratado Global de Comércio de Armas. Alguns têm outras obrigações legais, como membros da UE ou sob as leis domésticas, de não exportar armas usadas para cometer crimes de guerra. Ao persistir na transferência de armas para os Emirados Árabes Unidos, apesar de provas esmagadoras de que as armas estão sendo usadas em crimes de guerra e outras violações graves no Iêmen, eles estão desrespeitando essas obrigações" (ANISTIA INTERNACIONAL, 2019).
} 
Cumpre salientar, à título exemplificativo, o investimento e o apoio bélico às forças da coalizão: estima-se que a Alemanha, de janeiro a setembro de 2018, aprovou exportações relativas acerca de $€ 416$ milhões para a Arábia Saudita, ao mesmo tempo em que, também, aprovou exportações de mais de $€ 40$ milhões para os EAU (DW, 2019), fato que contradiz as ações tomadas pelo país, visto que, no início de 2018, a Chanceler alemã, Angela Merkel, assinou um acordo de proibição de exportação para Estados "diretamente" envolvidos no conflito, denotando o afrouxamento do cumprimento do acordo em prol de seus interesses econômicos nacionais (DW, 2019).

De mesmo modo, em 2019, o Congresso dos Estados Unidos votou a favor do bloqueio de venda de armamentos para os países da coalizão, decisão vetada pelo então presidente Donald Trump, sob o pressuposto de que, mesmo que o país pare de fornecer armamentos para a coalizão, esta procurará outros fornecedores, o que, "secretamente", prejudicaria o grande e lucrativo comércio bélico estadunidense (SENADO..., 2019). Para solução parcial da questão, foi introduzida, nos Estados Unidos, a 'Lei de Emergências Falsas da Arábia Saudita' (SAFE, na sigla em inglês - projeto que visa à supervisão de grandes vendas de armas (LANDLER; BAKER, 2019).

Além disso, o Reino Unido caracterizou a venda de armas para o país saudita como ilegal, visto que, inicialmente, não se considerava que o uso de tais equipamentos poderia vir a causar violações de direito internacional (AFP, 2019) - ato que, porém, foi revisto em 2020, retomando-se a venda de armas (AFP, 2020). A França, até então, não tomou medidas para conter a disseminação de seus armamentos em território iemenita, já havendo declarado que, recentemente, não exportou para o país, apesar de vestígios apontarem o oposto (RFI, 2019). ${ }^{21}$

Dessa forma, a partir do exposto, é possível compreender as dinâmicas que possibilitam a forte atuação de mercenários no conflito no Iêmen, como são atraídos por esse mercado e, também, como nele são mantidos, com o intenso fornecimento de equipamentos militares e consideráveis remunerações. Entende-se, também, como essa sistemática favorece, diretamente, às ações de violação dos princípios do direito internacional, particularmente, no escopo do Direito Internacional Humanitário, proferidas pelos Estados envolvidos, personificados na figura desses mercenários contratados através

\footnotetext{
21 "Since the war began in 2015, the coalition has used French tanks and armored vehicles to reinforce the Saudi border and defend Emirati military outposts in Yemen. The Saudis have stationed French long-range artillery guns along its border, capable of firing deep into Yemen's northern governorates, while the Emiratis have piloted French multiengine fighter planes, equipped with French laser-targeting technology. And both Saudi Arabia and the UAE have used French warships to enforce the coalition blockade against the country" (EMMONS, 2019).
} 
Campos Neutrais - Revista Latino-Americana de Relações Internacionais Vol. 2, $\mathrm{N}^{\mathrm{O}}$ 3, Setembro-Dezembro de 2020. Santa Vitória do Palmar - RS.

de EMSPs, fato que será, por fim, analisado à luz da jurisdição do Tribunal Penal Internacional.

\section{O tribunal penal internacional e a responsabilização de mercenários contratados e outros autores}

O TPI é um tribunal independente do sistema ONU, criado em 1998, a partir do Estatuto de Roma, possuindo jurisdição complementar em relação ao aparato jurídico dos Estados signatários para investigar e julgar indivíduos que cometam crimes internacionais. A sua jurisdição temporal (ratione temporis) abrange crimes cometidos a partir do dia $1^{\circ}$ de julho de 2002, quando o Estatuto de Roma entrou em vigor (ICC, 1998, art. 11). No tocante à sua jurisdição material (ratione materiae), o tribunal é responsável pelo julgamento de crimes internacionais, tais como, crimes de guerra, crimes contra a humanidade, crime de agressão e genocídio (ICC, 1998, art. 5). Em relação aos atos recentes no Iêmen, atenta-se para os dois primeiros.

No caso de crimes contra a humanidade, esses englobam os atos cometidos de forma sistemática ou generalizada contra a população civil, por meio de assassinato; extermínio; escravidão; aprisionamento ou qualquer violação de liberdade física; tortura; estupro, gravidez, escravidão sexual, prostituição e esterilização forçada; perseguição contra qualquer grupo por motivações de caráter político, racial, nacional, étnico, religioso, de gênero ou outra forma de discriminação; desaparecimento forçado; crime de apartheid e quaisquer atos desumanos que causem sofrimento ou que afetem a saúde física e mental (ICC, 1998, art. 7). Por sua vez, os crimes de guerra são atos cometidos como parte de um plano ou política, por meio da violação das Convenções de Genebra de 1949, como tortura; assassinatos em série; tratamentos desumanos; destruição e apropriação de propriedade, principalmente, ataques intencionais/bombardeios a civis ou a indivíduos, a instalações, a unidades e a veículos de assistência humanitária; e a manutenção de reféns ou prisioneiros de guerra (ICC, 1998, art. 8).

Em relação à jurisdição espacial, é de sua competência julgar crimes internacionais quando (a) cometido no território de um Estado Parte (princípio da territorialidade); (b) cometido por um nacional de um Estado Parte (princípio da personalidade ativa); (c) através de uma declaração de um Estado não signatário, caso o crime tenha sido de autoria de seu nacional ou em seu território; (d) ou, em última instância, a partir da indicação do Conselho de Segurança, garantindo jurisdição ao Tribunal (ICC, 1998, art. 12). Importante salientar que de todos atores citados neste texto, apenas a Austrália, Chile e Colômbia 
Campos Neutrais - Revista Latino-Americana de Relações Internacionais Vol. 2, $\mathrm{N}^{0}$ 3, Setembro-Dezembro de 2020. Santa Vitória do Palmar - RS.

ratificaram o Estatuto.

Ainda em relação aos aspectos legais contidos no Estatuto, insta pontuar os arts. 25 e 28 por relacionarem-se à temática tratada no caso do Iêmen. $\mathrm{O}$ primeiro refere-se à Responsabilidade Criminal Individual daquele que (a) comete crime individualmente, coletivamente ou, ainda, através de uma outra pessoa; (b) ordena ou solicita um crime que ocorreu ou que se tentou; (c) facilita ou contribui com o cometimento de tal crime, incluindo a concessão de meios para tal (ICC, 1998, art. 25). O segundo, por sua vez, complementa tal jurisdição referindo-se à responsabilidade de comandantes e outros superiores, quando (a) suas forças subordinadas cometerem o crime; (b) o comandante deveria ter sabido que os crimes estavam sendo cometidos sob sua tutela; (c) o comandante não se utilizou de todos os meios para prevenir o cometimento de crimes (ICC, 1998, art. 28).

Por fim, ainda, cumpre salientar o aspecto procedimental, mais especificamente, quanto a quem pode denunciar uma situação ao TPI. Esta questão está prevista no art. 14 e 15(2), do Estatuto, apontando que, além de os Estados-partes terem essa prerrogativa, o promotor, também, poderá iniciar uma investigação proprio motu, a qual poderá ser instigada por informações recebidas por Estados (membros ou não), por órgãos da ONU, por outras organizações intergovernamentais ou não governamentais, assim como por qualquer outra fonte, a exemplo de advogados (ICC, 1998, arts. 14 e 15). Para que o inquérito seja instaurado, uma vez verificados os critérios de (a) competência, (b) razoabilidade das informações, (c) complementariedade, e (d) gravidade do fato (ICC, 1998, art. 53), o Procurador do TPI poderá solicitar a abertura de um inquérito contra um indivíduo ao Juízo de Instrução (ICC, 1998, arts. 15 e 17).

Feitas essas considerações preliminares, cabe dizer que, em 2017, a Organização Árabe para os Direitos Humanos, no Reino Unido (AOHR/UK, na sigla em inglês), entregou ao TPI uma solicitação de investigação sobre os atos cometidos em território iemenita, assim como enviou cartas aos Estados onde ocorreu recrutamento mercenário Colômbia, Chile, Austrália, El Salvador e Panamá -, pedindo que retirassem seus nacionais do conflito, porém não houve prosseguimento do pedido (KOLTONOWSKI, 2017; AFP, 2017). Dentre os atos cometidos, cita-se o intenso uso de ataques aéreos perpetrados pela coalizão, que atingiram, por exemplo, áreas residenciais, hospitais e mercados, bem como casos de tortura, desaparecimento forçado, assassinato e violência sexual e de gênero ${ }^{22}$ (KOLTONOWSKI, 2017; OHCHR, 2018).

\footnotetext{
${ }^{22}$ Dentro desse cenário, também, são observados crimes de guerra cometidos pelo movimento Houthi, mas a presente pesquisa destaca, apenas, os atos cometidos pela coalizão, figurados nos mercenários.
} 
Os atos continuaram e três casos de ataques aéreos comandados pela coalizão são notórios: em 2016, um ataque ao hospital da Médecins sans Frontières contabilizou 19 mortos (MSF, 2018); em 2018, um ataque aéreo a uma escola em Dahyan, no qual 40 crianças foram mortas (BAKHSH, 2018) e, também, um ataque a uma festa de casamento na cidade de Bani Qais, controlada pelas forças Houthi, que matou 20 pessoas (UN, 2020). Além disso, desde 2016, o Painel de Peritos das Nações Unidas notificou 11 vezes os países da coalizão sobre cerca de 40 ataques aéreos, mas não obteve resposta e concluiu que os princípios de distinção, precaução e proporcionalidade estavam sendo violados, como apresentou, em seu relatório, de 2019 (AMNESTY INTERNATIONAL, 2019). Cabe acrescentar que, em 2015, a Human Rights Watch já havia apontado para o uso indiscriminado de força, principalmente, no que concerne aos ataques aéreos, enfatizando a responsabilidade dos Comandantes Militares de escolher um meio que minimize os danos a civis, uma vez que, se as armas utilizadas no conflito não são precisas, não devem ser utilizadas (HRW, 2019).

Em sequência, o Painel, também, investigou mais 13 casos de prisão arbitrária, tratamentos desumanos, desaparecimento forçado e tortura, assim como a informação de que 54 pessoas teriam sofrido os mesmos abusos no período de 2016 a 2019, na cidade de Áden, promovidos pelo Cinturão de Segurança, pelo conjunto de milícias e pelos mercenários apoiados, financeiramente e militarmente, pelos Emirados Árabes Unidos (AMNESTY INTERNATIONAL, 2019). Neste último ano, a HRW (2019) relatou tais abusos impulsionados por representantes do governo emirati e das forças do governo iemenita. Por fim, destaca-se, também, a violência de gênero, visto que, "em 2016, o Escritório das Nações Unidas para a Coordenação de Assuntos Humanitários relatou que 2,6 milhões de mulheres e meninas estavam em risco de violência de gênero, um aumento de $63 \%$ das pessoas em risco desde o início do conflito" (U.S. DEPARTMENT OF STATE, 2019).

Nesse momento, permite-se compreender a fundamentação das acusações contra líderes da coalizão ao TPI, porém cabe relembrar que a jurisdição deste é complementar à jurisdição doméstica dos países que tenham ratificado o Estatuto - o que não é o caso da Arábia Saudita, dos Emirados Árabes e do Iêmen. Quer isso dizer que, mesmo diante de uma inação ou de uma impossibilidade de julgamento, nos termos do art. 17, do Estatuto (ICC, 1998), por parte desses Estados em relação aos seus nacionais, independentemente do local do crime, ou mesmo o Iêmen, forte no local da conduta lesiva, o TPI não poderia exercer sua jurisdição pelos critérios da territorialidade e da personalidade ativa já pontuados. 
Especificamente, no caso do Iêmen, mesmo se ele fosse membro do Tribunal e tivesse a intenção de julgar, a sua incapacidade seria avultada na medida em que o país enfrenta adversidades em seu aparato jurídico, já que os Houthi controlam o Tribunal Criminal Especializado de Sanaa e o utilizam como instrumento de ataque à oposição, dificultando, ainda mais, a tomada de medidas cabíveis pelo governo (MWATANA, 2020). Além disso, o país contribui para a perpetuação de crimes de guerra e contra a humanidade em seu território, sem tomar medidas eficazes de contenção dos mesmos, seja por não efetivar a Convenção contra Tortura e outros Tratamentos, contra Penas Cruéis, Desumanas ou Degradantes, de 1984, ratificada pelo país (MWATANA, 2020), seja por violar as Convenções de Genebra de 1949.

Imperioso mencionar que as Convenções de 1949 foram ratificadas pelos dois principais países da coalizão e, também, violada por estes, valendo enfatizar o common article three (art. 3, comum às quatro Convenções de Genebra), que estipula às partes a atuarem de modo a garantir que os tratados sejam eficazmente implementados e proíbe, em relação às pessoas que não participam diretamente do conflito,

(a) os atentados à vida e à integridade física, em particular o homicídio sob todas as formas, as mutilações, os tratamentos cruéis, torturas e suplícios; (b) as tomadas de reféns; (c) as ofensas à dignidade das pessoas, especialmente os tratamentos humilhantes e degradantes; e (d) as condenações proferidas e as execuções efetuadas sem julgamento prévio por um tribunal regularmente constituído, que ofereça todas as garantias judiciais reconhecidas como indispensáveis pelos povos civilizados (CICV, 2017).

Em acréscimo, vale ressaltar que a Arábia Saudita ratificou a Convenção Internacional contra o Recrutamento, o Uso, o Financiamento e o Treinamento de Mercenários adotada em 1989, que prevê a atuação dos Estados-partes, de modo a garantir a prevenção desta modalidade, observando, assim, outra violação saudita, que, apesar de, não diretamente, contribuir com o treinamento e com a negociação, como faz os EAU, ajuda financeiramente, concedendo equipamentos militares que compra dos Estados Unidos, além de se portar de maneira omissa frente às investidas promovidas pela outra grande potência da coalizão.

Apesar de todas as citadas violações, os Estados da coalizão ou seus nacionais, assim como o próprio governo iemenita, não podem ser julgados pelo Tribunal Penal Internacional, como consta no relatório publicado por este ao final de 2019. Nele, o órgão alega que não possui jurisdição territorial para investigar ou para julgar crimes cometidos 
no território iemenita, uma vez que não ratificou o Estatuto de Roma; porém, que poderia fazê-lo em relação as nacionais de Estados signatários que atuam no conflito, como a Colômbia, Austrália, Chile, Panamá e El Salvador - estes último, para crimes cometidos apenas após 1 de junho de 2016, forte na data de adesão do mesmo ao TPI (ICC, 2019).

Afirmou, ainda, que não há precedência de que os crimes de guerra teriam sido cometidos por nacionais dos Estados-parte, em que pese informações taxadas como insuficientes de nacionais que estariam atuando em favor das forças armadas dos Emirados Árabes Unidos:

Accordingly, while the Office remains concerned about the reported widespread violations of international humanitarian law in the context of the armed conflict in Yemen, it has concluded that, based on the information available at this stage, it does not appear that State Party nationals engaged as mercenaries in Yemen are responsible for the crimes alleged in the communication (ICC, 2019, p. 17 - para. 55). ${ }^{23}$

Apesar do pronunciamento do Tribunal sobre o caso, diversos crimes continuam a ser cometidos sem a devida responsabilização dos envolvidos diretos ou indiretos no conflito. Verifica-se, assim, a não persistência do Tribunal em investigar e julgar, fielmente, os nacionais envolvidos no conflito, que são usados como instrumento para o cometimento de gravíssimos crimes por outros Estados que não são partes do Estatuto de Roma, falhando em cumprir com os objetivos pelos quais o Tribunal foi arquitetado, que era, justamente, o combate à impunidade.

Não só isso, os países que fornecem essa visível 'exportação de segurança' continuam a se destacar no conflito, com o recorrente relato da atuação de mercenários pelas imprensas internacionais e a não tomada de medidas cabíveis de investigação e julgamento dos nacionais ou das EMSPs que facilitam esse intercâmbio, podendo ser caracterizados como omissos e alheios às obrigações primárias previstas no Estatuto. Aliás, a violação de outras Convenções contribuem para a atuação desses mercenários em solo iemenita também não é questionada, não havendo nenhum tipo de procedimento no âmbito da Corte Internacional de Justiça nesse sentido - tribunal responsável pelo processamento de Estados (UN, 1945, art. 34) -, muito porque, como discorrido, o conflito garante manutenção de poder e de grandes benefícios econômicos às grandes potências internacionais.

\footnotetext{
${ }^{23}$ Tradução livre: Assim, enquanto o Escritório permanece preocupado em relação aos relatos de violações generalizadas ao Direito Internacional Humanitário no contexto do conflito armado no Iêmen, conclui-se que, baseado em informações disponíveis neste momento, não se parece que nacionais de Estados Parte que se envolvem como mercenários no Iêmen são responsáveis pelos crimes apresentados no comunicado
} 


\section{Considerações finais}

O conflito no Iêmen completa seu sexto ano mais sangrento, agregando-lhe o título de pior crise humanitária do mundo, mesmo com um número de mortos abaixo do que o observado em outras crises humanitárias, como no caso sírio, fato que se comprova pelo caráter multifacetado do conflito, que envolve diversos grupos internos - que, por vezes, se unem e, por vezes, combatem entre si -, e pela interferência direta de outros países árabes, da chamada coalizão indireta de grandes potências mundiais. Além disso, sua complexidade é ampliada com o surgimento de um potencial ator internacional, os mercenários, que adentram ao conflito através de Empresas Militares de Segurança Privada, um ator internacional secundário.

Apesar de tantos atores, este conflito caracteriza-se como não internacional, uma vez que os protagonistas são provenientes do próprio país, representados na figura do governo central e do movimento Houthi e de procuração (proxy war), já que o apoio da coalizão e das grandes potências é fornecido ao primeiro grupo, enquanto o Irã, uma potência na região árabe, apoia o segundo, na tentativa de expandir suas influências e controlar áreas de interesse no Iêmen, país detentor de importantes pontos geopolíticos.

Todas essas caracterizações permitiram tornar os Mercenários como ponto-chave do conflito, já que é possível analisar que todas as dinâmicas, atualmente, ocorrem ao seu entorno. Sua utilização permite benefícios a todos os Estados envolvidos e às EMSPs: as grandes potências fornecem equipamentos e armamentos, o que contribui para a manutenção do status quo, isto é, da manutenção destes Estados como grandes potências, não só econômicas mas também bélicas. Ademais, permite, ainda, um controle mais aproximado de uma das áreas mais estratégicas do globo, vez que o Iêmen não só se situa à beira do Golfo Pérsico, região fundamental para a indústria petrolífera, mas igualmente está situado em um local verdadeiramente estratégico no que diz respeito à contenção de grupos extremistas, como a Al Qaeda e o Estado Islâmico, ou acompanhamento de outros Estados taxados enquanto "inimigos", como o Irã, o qual se faz significativamente presente na região por meio da sua indústria bélica e é considerado uma constante ameaça aos Estados Unidos.

Em relação às EMSPs, as quais, em sua maioria, encontram-se sediadas nos Estados Unidos, recebem armamentos, treinamento e técnicas de inteligência do país sede, sendo responsável pelo treinamento de militares de Forças Armadas de diversos países latino-americanos, sob o pressuposto de combater adversidades internas, mas que, na realidade, lhe garante um maior controle sobre outros países, permitindo que se concretize 
o processo de "Exportação de Segurança" desses militares altamente treinados para outras nações, principalmente, para aqueles que se encontram em conflito no Oriente Médio ou mesmo na África, em troca de remunerações melhores, aumentando, exponencialmente, a procura e o lucro dessas empresas.

A utilização desses mercenários, por nações que não são as suas, garante uma complexidade ainda maior ao conflito iemenita, pois as ações para a resolução das hostilidades dependem de todas as partes envolvidas, o que não é observado no país. Em relação às forças do movimento Houthi, que, também, agem violando o direito internacional, uma resolução seria facilitada caso o governo central do Iêmen não fosse fragmentado e apoiado por grupos que, na realidade, atuam, exclusivamente, em prol de seus interesses, comumente apresentando divergências.

A atuação dos Emirados Árabes Unidos, também, é decisiva, em que pese a Arábia Saudita esteja à frente da coalizão. Este fato se comprova pela constante interferência e aliança do Estado emirati com pequenos grupos no Sul do país, como o Conselho de Transição do Sul, mesmo que, explicitamente, apoie o governo central, a fim de controlar, estrategicamente, sua área de interesse e o seu contato direto com as EMSPs para recebimento de mercenários - que lutarão nesses grupos - e para apoio das grandes potências no que diz respeito a fornecimento bélico.

Essa constante interferência de outros países foi acompanhada de uma série de violações de direito internacional, configuradas como crimes de guerra e crimes contra a humanidade, que são realizadas por mercenários sob o comando de chefes emirates ou sauditas. Essa situação possibilita a não responsabilização dos chefes pelos atos cometidos, uma vez que seus países de origem não ratificaram o Estatuto de Roma. Outrossim, a responsabilização poderia ser atribuída diretamente a alguns mercenários (ou até mesmo a alguns subchefes das investidas), uma vez que, como aludido, muito são nacionais de Estados signatários do Estatuto e, logo, poderiam ser submetidos à jurisdição do Tribunal Penal Internacional pelo critério da personalidade ativa.

Anterior a uma postura do Tribunal, porém, seria necessária uma postura dos Estados "exportadores", que, convenientemente, não tomam medidas duras e punitivas contra seus nacionais ou, até mesmo, contra o negócio lucrativo promovido pelas EMSPs o qual, atualmente, é muito mais atrativo para os militares do que continuar atuando pelas Forças Armadas nacionais, haja vista a sua desregulamentação não depender dos esforços soft law do Documento de Montreux, o qual poderia servir de base para a adoção de medidas mais rígidas e eficazes. 
Embora a abertura de uma investigação tenha acontecido, o TPI não reconhece haver provas suficientes para indiciar os mercenários envolvidos no conflito, o que contribui para uma continuação, certamente, de maneira cada vez mais sangrenta, do cometimento de crimes de guerra e/ou de crimes contra a humanidade, que afetam, principalmente, civis, em particular, mulheres e crianças. Nesse momento, cabe a reflexão da real efetividade deste Tribunal enquanto um foro capaz de garantir a resolução de um conflito por meio do exercício jurisdicional contra os responsáveis pelo cometimento contínuo de atrocidades, afinal, o que se observa, nesse caso, é a imobilização e certo desestímulo político em dar continuidade a uma investigação mais efetiva, provada, ainda mais, pelas diversas informações e pelos relatórios propiciados pelas Nações Unidas e por outras Organizações Internacionais que são de acesso público e que contradizem o parecer dado pela corte situada na Haia.

Desta forma, talvez fosse necessário maior atuação do Conselho de Segurança da ONU no caso do conflito do Iêmen, a fim de que a situação fosse indicada ao TPI, retirando as limitações estatutárias impostas quanto à sua jurisdição territorial e pessoal. Outrossim, cabe lembrar que a medida só seria adotada por meio de uma Resolução, aprovada sem vetos de membros permanentes e com base no Capítulo VII da Carta da ONU - o que, igualmente, parece bastante distante de acontecer, especialmente, quando os Estados Unidos, França e Reino Unido ocupam um assento permanente no órgão onusiano e lucram, sobremaneira, com a venda de armamento para as partes beligerantes no Iêmen.

Aliás, esse é o grande problema do conflito no tocante aos mercenários e às graves ações/condutas perpetradas por eles, pois personificam os Estados estrangeiros, os quais são os grandes protagonistas desse conflito, especialmente, quando este permite a manutenção de poder e de imensos ganhos econômicos para as grandes potências que, politicamente, orquestram as relações internacionais e acabam por ser cúmplices dos crimes cometidos no Iêmen, sem qualquer tipo de reprimenda - seja em relação aos seus nacionais, seja enquanto Estado. Nesse passo, tem-se que esse cenário precisa ser revertido, sendo, possivelmente, um step forward importante repensar a privatização dos conflitos.

\section{Referências}

AFP. Separatistas do sul do Iêmen proclamam autonomia e crise se agrava. IstoÉ Dinheiro, 26 abr. 2020. Disponível em: https://www.istoedinheiro.com.br/separatistas-do-sul-do-iemen-proclamamautonomia-e-crise-se-agrava/. Acesso em: 31 out. 2020 
Campos Neutrais - Revista Latino-Americana de Relações Internacionais Vol. 2, $\mathrm{N}^{\mathrm{O}}$ 3, Setembro-Dezembro de 2020. Santa Vitória do Palmar - RS.

. ICC called on to investigate war crimes committed by UAE in Yemen. Daily Sabah, 27 nov. 2017. Disponível em. https://www.dailysabah.com/mideast/2017/11/27/icc-called-on-toinvestigate-war-crimes-committed-by-uae-in-yemenAcesso em: 31 out. 2020

. Reino Unido vai revisar entrega de armas à Arábia Saudita. Correio do Povo, 20 jun. 2019. Disponível em: https://www.correiodopovo.com.br/notícias/mundo/reino-unido-vai-revisarentrega-de-armas-à-arábia-saudita-1.346576. Acesso em: 31 out. 2020

. Reino Unido retomará venda de armas para a Arábia Saudita. Estado de Minas, 07 jul. 2020. Disponível em: https://www.em.com.br/app/noticia/internacional/2020/07/07/interna_internacional,1163567/reinounido-retomara-venda-de-armas-para-a-arabia-saudita.shtml. Acesso em: 31 out. 2020

AMNESTY INTERNATIONAL. Yemen: Huthi-run court sentences 30 political opposition figures to death following sham trial. London, 9 jul. 2019. Disponível em: https://www.amnesty.org/en/latest/news/2019/07/yemen-huthi-run-court-sentences-30-politicalopposition-figures-to-death-following-sham-trial/. Acesso em: 31 out. 2020

Iêmen: Emirados Árabes munem milícias com armas ocidentais. Disponível em: <https://anistia.org.br/noticias/iemen-emirados-arabes-munem-milicias-com-armas-ocidentais/>. Acesso em: 11 ago. 2020.

Yemen: Submission to the UN Human Rights Committee. Refworld. 104 Session of the Human Rights Committee. London, Mar., 2012. Disponível em: <https://www.refworld.org/pdfid/4f48e4382.pdf>. Acesso em: 24 ago. 2020.

AUSTRALIA.Parliament of Australia. Yemen - the 'worst humanitarian crisis in the world' continues. Canberra, 6 dez. 2020. Disponível em: <https://parlinfo.aph.gov.au/parlInfo/download/library/prspub/6375089/upload_binary/6375089.pd f>. Acesso em: 11 ago. 2020.

ARWA - ARABIAN RIGHTS WATCH ASSOCIATION. Use of foreign mercenaries. Disponível em: <http://arwarights.org/foreign-mercenaries-file>. Acesso em: 24 ago. 2020.

BAKHSH, Sumaya. Families of Yemen bus strike victims despair at global response. BBC, 8 set 2018. Disponível em: https://www.bbc.com/news/world-middle-east-45449978. Acesso em: 31 out. 2020

BBC. Por que há uma guerra no lêmen e qual é o papel das potências internacionais? BBC, 23 nov. 2018. Disponível em: <https://www.bbc.com/portuguese/internacional-46322964>. Acesso em: 10 ago. 2020 .

Yemen crisis: why is there a war? BBC, 19 jun. 2018.Disponível em: <https://www.bbc.com/news/world-middle-east-29319423>. Acesso em: 11 ago. 2020.

BEAUMONT, Peter. Death toll in Yemen war reaches 100,000. The Guardian, 31 out. 2019. Disponível em: https://www.theguardian.com/world/2019/oct/31/death-toll-in-yemen-war-reaches100000. Acesso em: 31 out. 2020

CARLSEN, Laura. Mercenaries in Yemen: the US Connection. Near East News Agency - NENA, 9 dec. 2015. Disponível em: https://nena-news.it/mercenaries-in-yemen-the-us-connection/. Acesso em: 31 out. 2020

COSOY, Natalino. Has plan Colombia really worked? BBC, 4 fev. 2016. Disponível em: <https://www.bbc.com/news/world-latin-america-35491504>. Acesso em: 24 ago. 2020.

DW. German arms companies accused of aiding war crimes in Yemen. DW, 12 dez. 2019. Disponível em: <https://www.dw.com/en/german-arms-companies-accused-of-aiding-war-crimesin-yemen/a-51637420>. Acesso em: 11 ago. 2020.

EL TIEMPO. Los colombianos que pelearán otra guerra en el Golfo. El Tiempo, 17 out. 2015. Disponível em: <https://www.eltiempo.com/archivo/documento/CMS-16406208>. Acesso em: 24 ago. 2020. 
Campos Neutrais - Revista Latino-Americana de Relações Internacionais Vol. 2, $\mathrm{N}^{\mathrm{O}}$ 3, Setembro-Dezembro de 2020. Santa Vitória do Palmar - RS.

EMMOS, Alex. Secret Report reveals Saudi Incompetence and Widespread use of U.S. Weapons in Yemen. The Intercept, 15 abr. 2019. Disponível em: https://theintercept.com/2019/04/15/saudiweapons-yemen-us-france/. Acesso em: 31 out. 2020

FRANCE PRESSE. Separatistas do Iêmen renunciam à autonomia e aceitam acordo de paz. G1, 29 jul. 2020. Disponível em: https://g1.globo.com/mundo/noticia/2020/07/29/separatistas-do-iemenrenunciam-a-autonomia-e-aceitam-acordo-de-paz.ghtml. Acesso em: 31 out. 2020

FOLHA DE SÃO PAULO. Leia trecho de "História dos Mercenários". Folha de São Paulo, 9 nov. 2012. Disponível em: <https://www1.folha.uol.com.br/livrariadafolha/1183026-leia-trecho-dehistoria-dos-mercenarios.shtml>. Acesso em: 11 ago. 2020.

G1. Iêmen: governo e separatistas assinam acordo de paz. G1, 05 nov. 2019.Disponível em: <https://g1.globo.com/mundo/noticia/2019/11/05/iemen-governo-e-separatistas-assinam-acordode-paz.ghtml>. Acesso em: 11 ago. 2020.

Separatistas do Iêmen renunciam à autonomia e aceitam acordo de paz. G1, 29 set. 2020.Disponível em: <https://g1.globo.com/mundo/noticia/2020/07/29/separatistas-do-iemenrenunciam-a-autonomia-e-aceitam-acordo-de-paz.ghtml>. Acesso em: 11 ago. 2020.

GUEDES, Henrique Lenon F. Privatização da Guerra: mercado e regulação de empresas militares privadas. Belo Horizonte: Arraes, 2017.

HAGER, Emily B.; MAZZETTI, Mark. Emirates Secretly Sends Colombian Mercenaries to

Yemen Fight. The New York Times, 25 nov. 2015. Disponível em: https://www.nytimes.com/2015/11/26/world/middleeast/emirates-secretly-sends-colombianmercenaries-to-fight-in-yemen.html. Acesso em: 31 out. 2020

HERAS, Nicholas. 'Security Belt': The UAE's Tribal Counterterrorism Strategy in Yemen. The Jamestown Foundation, 14 jun. 2018. Disponível em: https://jamestown.org/program/securitybelt-the-uaes-tribal-counterterrorism-strategy-in-yemen/. Acesso em 31 out. 2020.

HRW - HUMAN RIGHTS WATCH. World Report 2019: Yemen. New York, s/d. Disponível em: <https://www.hrw.org/world-report/2019/country-chapters/yemen>. Acesso em: 11 ago. 2020.

Q \& A on the Conflict in Yemen and International Law. New York, s/d. Disponível em: <https://www.hrw.org/news/2015/04/06/q-conflict-yemen-and-international-law>. Acesso em: 24 ago. 2020.

ICRC - INTERNATIONAL COMMITTEE OF THE RED CROSS. Artigo $3^{\circ}$ comum às quatro Convenções de Genebra. Genebra, 26 set. 2016. Disponível em: $<$ https://www.icrc.org/pt/document/artigo-3o-comum-quatro-convencoes-de-genebra $>$. Acesso em: 24 ago. 2020.

O Direito Internacional Humanitário e as empresas militares e de segurança

privadas. Genebra, 10 dez. $2013 . \quad$ Disponível em:
<https://www.icrc.org/pt/doc/resources/documents/faq/pmsc-faq-150908.htm>. Acesso em: 24 ago. 2020.

Treaties, States Parties and Commentaries: Saudi Arabia. Disponível em: <https://ihldatabases.icrc.org/applic/ihl/ihl.nsf/vwTreatiesByCountrySelected.xsp?xp_countrySelected=SA>. Acesso em: 24 ago. 2020.

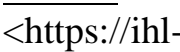

Treaties, States Parties and Commentaries: United Arab Emirates. Disponível em: databases.icrc.org/applic/ihl/ihl.nsf/vwTreatiesByCountrySelected.xsp?xp_countrySelected=AE> . Acesso em: 24 ago. 2020.

Treaties, States Parties and Commentaries: Saudi Yemen.Disponível em: <https://ihldatabases.icrc.org/applic/ihl/ihl.nsf/vwTreatiesByCountrySelected.xsp?xp_countrySelected=YE>. Acesso em: 24 ago. 2020.

Protocolo I Adicional às Convenções de Genebra de 12 de agosto de 1949 relativo à 
Campos Neutrais - Revista Latino-Americana de Relações Internacionais Vol. 2, $\mathrm{N}^{\mathrm{O}}$ 3, Setembro-Dezembro de 2020. Santa Vitória do Palmar - RS.

Proteção das Vítimas dos Conflitos Armados Internacionais. Genebra, 7 dez. 1979.Disponível em: <http://www.planalto.gov.br/ccivil_03/Decreto/1990-1994/D0849.htm>. Acesso em: 11 ago. 2020 .

Montreux Document on pertinent international legal obligations and good practices for States related to operations of private military and security companies during armed conflict. $\quad$ Montreux, 2008. Disponível em: $<$ https://www.icrc.org/en/doc/assets/files/other/montreux-document-eng.pdf >. Acesso em: 18 ago. 2020.

ICC - INTERNATIONAL CRIMINAL COURT. Report on Preliminary Examination Activities 2019. Disponível em: <https://www.icc-cpi.int/itemsDocuments/191205-rep-otp-PE.pdf〉. Acesso 11 ago. 2020.

Rome Statute. 1998.Disponível em: <https://www.icc-cpi.int/NR/rdonlyres/ADD16852AEE9-4757-ABE7-9CDC7CF02886/283503/RomeStatutEng1.pdf>. Acesso em: 21 ago. 2020.

INTERNATIONAL CRISIS GROUP. Crisis Group Yemen Update \#11. Disponível em: $<$ https://www.crisisgroup.org/middle-east-north-africa/gulf-and-arabian-peninsula/yemen/crisisgroup-yemen-update-11> Acesso em: 11 ago. 2020.

KOLTONOWSKI, Austin. Rights group urges ICC to investigate mercenaries in Yemen. Jurist, 28 nov. 2017. Disponível em: https://www.jurist.org/news/2017/11/rights-group-urges-icc-toinvestigate-mercenaries-in-yemen/. Acesso em: 31 out. 2020.

LANDLER, Mark; BAKER, Peter. Trump Vetoes Measure to Force End to U.S. Involvement in Yemen War. The Washington Post. 16 abr. 2019. Disponível em: https://www.nytimes.com/2019/04/16/us/politics/trump-veto-yemen.html?auth=login-facebook.

Acesso em: 31 out. 2020

LAWANDA, Kathlnee. Entrevista: O que é um conflito armado não internacional?. ICRC, 2012. Disponível em: https://www.icrc.org/pt/doc/resources/documents/interview/2012/12-10-niac-noninternational-armed-

conflict.htm\#: :text=Um\%20conflito\%20armado\%20não\%20internacional\%20(ou\%20interno)\%2 0refere-se,no\%20território\%20de\%20um\%20Estado. Acesso em: 31 out. 2020

MCFATE, Sean. Mercenaries and War: Understanding Private Armies Today.NDU: National Defense University Press, 2019. Disponível em: <https://ndupress.ndu.edu/Portals/68/Documents/strat-monograph/mercenaries-and-war.pdf $>$.

Acesso em: 11 ago. 2020.

MSF - MEDECINS SANS FRONTIERES. MSF releases detailed documentation of attacks on two medical facilities ahead of UNSC closed session on protection of medical mission. Geneve, 27 set. 2016. Disponível em: https://www.msf.org/yemen-msf-releases-detailed-documentationattacks-two-medical-facilities-ahead-un-security-council. Acesso em: 31 out. 2020.

MWATANA. In the darkness: Abusive Detention, Disappearance and Torture in Yemen's Unofficial Prisions (May 2016 - April 2020). Mawatana for Human Rights, Saana, jun. 2020. Disponível em: <https://mwatana.org/wp-content/uploads/2020/06/In-the-Darkness.pdf>. Acesso em: 24 ago. 2020.

OHCHR - OFFICE OFH THE HIGH COMMISSIONER OF HUMAN RIHGTS. Yemen: United Nations Experts point to possible war crimes by parties to the conflict. Geneva, 28 ago. 2018.Disponível em: <https://www.ohchr.org/EN/NewsEvents/Pages/DisplayNews.aspx?NewsID=23479\&LangID=E >. Acesso em: 24 ago. 2020.

ONU - NAÇÕES UNIDAS. ONU realiza esforços para implementar acordo internacional no Iémen. ONU News, 2 jan. 2019. Disponível em: <https://news.un.org/pt/story/2019/01/1653832>. Acesso em: 11 ago. 2020.

OSESGY - Office of the Special Envoy of the Secretary General to Yemen.. Briefing of the 
Campos Neutrais - Revista Latino-Americana de Relações Internacionais Vol. 2, $\mathrm{N}^{\mathrm{O}}$ 3, Setembro-Dezembro de 2020. Santa Vitória do Palmar - RS.

Special Envoy of the Secretary-General for Yemen. s/l, 20 ago. 2019.Disponível em: $<$ https://osesgy.unmissions.org/briefing-special-envoy-united-nations-secretary-general-yemenopen-session-security-council>. Acesso em: 11 ago. 2020.

REUTERS. Coalizão pró-governo do Iêmen racha, e separatistas tomam o controle de capital provisória. G1, $10 \quad$ ago. $2019 . \quad$ Disponível em: https://g1.globo.com/mundo/noticia/2019/08/10/coalizao-pro-governo-do-iemen-racha-eseparatistas-tomam-o-controle-de-capital.ghtml. Acesso em: 31 out. 2020

RFI. Site de investigação revela uso de armas francesas na guerra do Iêmen. RFI, 15 abr. 2010. Disponível em: https://www.rfi.fr/br/franca/20190415-site-de-investigacao-revela-uso-de-armasfrancesas-na-guerra-do-iemen. Acesso em: 31 out. 2020

ROSTON, Aram. A Middle East Monarchy Hired American Ex-Soldiers To Kill Its Political Enemies. This Could Be The Future Of War. Buzzfeed News, 16 out. 2018. Disponível em: https://www.buzzfeednews.com/article/aramroston/mercenaries-assassination-us-yemen-uae-speargolan-dahlan. Acesso em: 31 out. 2020

RYAN, Missy. U.N. report calls for alleged war crimes in Yemen to be referred to International Criminal Court. The Washington Post, 10 set. 2020. Disponível em: https://www.washingtonpost.com/national-security/un-report-calls-for-alleged-war-crimes-inyemen-to-be-referred-to-international-criminal-court/2020/09/10/3eb69194-f369-11 ea-927945d6bdfe145f_story.html. Acesso em: 31 out. 2020

SAFI, Michael; ROBERTSON, Joshua. This article is more than 4 years old Australian mercenary reportedly killed in Yemen clashes. The Guardian, 8 dec. 2015.Disponível em: $<$ https://www.theguardian.com/australia-news/2015/dec/09/australian-mercenary-reportedly-killedyemen-clashes>. Acesso em: 24 ago. 2020.

SENADO americano aprova legislação contra venda de armas à Arábia Saudita. Monitor do

Oriente Médio - MEMO, 26 jun. 2019. Disponível em: https://www.monitordooriente.com/20190626-senado-americano-aprova-legislacao-contra-vendade-armas-a-arabia-saudita/. Acesso em: 31 out. 2020

SHARP, Jeremy M. Yemen: Civil War and Regional Intervention. Washington D.C.: CRS, 2019. Disponível em: https://www.everycrsreport.com/files/20190917_R43960_0ae8aef063532aa48081bbedecd442b102 77aa42.pdf. Acesso em: 31 out. 2020.

TODD, Zoe. U.S. Weapons, Saudi Airstrikes, Yemeni Deaths: What a U.N. Report on War Crimes in Yemen Means for U.S.-Saudi Weapon Sales. Frontline, 1 out. 2019. Disponível em: https://www.pbs.org/wgbh/frontline/article/u-s-weapon-saudi-airstrikes-yemen. Acesso em: 31 out. 2020

UNICRIO - CENTRO DE INFORMAÇÕES DAS NAÇÕES UNIDAS NO BRASIL. Regulamentação de segurança privada internacional é necessária, afirmam especialistas da ONU. Rio de Janeiro, 30 abr. 2010. Disponível em: https://unicrio.org.br/e-necessarioregulamentar-acoes-de-militares-particulares-e-empresas-de-seguranca-que-agem-na-esferainternacional-afirmam-especialistas-da-onu/. Acesso em: 31 out. 2020

UNITED NATIONS. Statute of the International Court of Justice. 1945.Disponível em: <https://www.icj-cij.org/en/statute>. Acesso em: 24 ago 2020. Disponível

Security Council: Final report of the Panel of Experts on Yemen. Iran Watch.2020.

Humanitarian Affairs Chief Decries Widespread Famine in Yemen, Urging Immediate Security Council Action to Prevent 'Massive' Loss of Life, Economic Collapse. New York, 21 set. 2018. Disponível em: https://www.un.org/press/en/2018/sc13519.doc.htm. Acesso em: 31 out. 2020.

Security Council 8598th Meeting. New York, 20 ago. 2019. Disponível em: 
Campos Neutrais - Revista Latino-Americana de Relações Internacionais Vol. 2, $\mathrm{N}^{\mathrm{O}}$ 3, Setembro-Dezembro de 2020. Santa Vitória do Palmar - RS.

https://www.securitycouncilreport.org/atf/cf/\%7B65BFCF9B-6D27-4E9C-8CD3CF6E4FF96FF9\%7D/S_PV.8598.pdf. Acesso em: 31 out. 2020.

Security Council - Letter dated 27 January 2020 from the Panel of Experts on Yemen addressed to the President of the Security Council. New York, 27 jan. 2020. Disponível em: https://www.iranwatch.org/sites/default/files/final_report_of_the_panel_of_experts_on_yemen.pdf. Acesso em: 31 out. 2020

Training of Mercenaries. Disponível Financing and https://treaties.un.org/Pages/ViewDetails.aspx?src=IND\&mtdsg_no=XVIII-

$6 \&$ chapter=18\&clang=_en. Acesso em 31 out. 2020.

UNRIC - UNITED NATIONS REGIONAL INFORMATION CENTRE.da Iémen: a maior crise humanitária do mundo. s/l;s/d. Disponível em: <https://unric.org/pt/iemen-a-maior-crise-

humanitaria-do-mundo/>. Acesso em: 24 de ago. 2020.

U.S DEPARTMENT OF STATE. 2019 Country Reports on Human Rights Practices: Yemen. Disponível em: <https://www.state.gov/reports/2019-country-reports-on-human-rightspractices/yemen/>. Acesso em: 24 ago. 2020.

YEMEN facing largest famine the world has seen for decades, warns UN aid chief. UN News, 9 nov. 2017. Disponível em: https://news.un.org/en/story/2017/11/570262-yemen-facing-largestfamine-world-has-seen-decades-warns-un-aid-chief. Acesso em: 31 out. 2020 